Erratum

Anaesthesist $2021 \cdot 70$ (Suppl 1):S77

https://doi.org/10.1007/s00101-021-00964-1

Online publiziert: 22. April 2021

(c) Springer Medizin Verlag GmbH, ein Teil von Springer Nature 2021
Christina Massoth $\cdot$ Khaschayar Saadat-Gilani $\cdot$ Melanie Meersch ${ }^{1} \cdot$ HandiCAP Investigators

'Klinik für Anästhesiologie, operative Intensivmedizin und Schmerztherapie, Universitätsklinikum Münster, Münster, Deutschland

\title{
Erratum zu: Der Einfluss intraoperativer Anästhesistenwechsel auf das postoperative Patientenoutcome - die randomisiert-kontrollierte HandiCAP-Studie
}

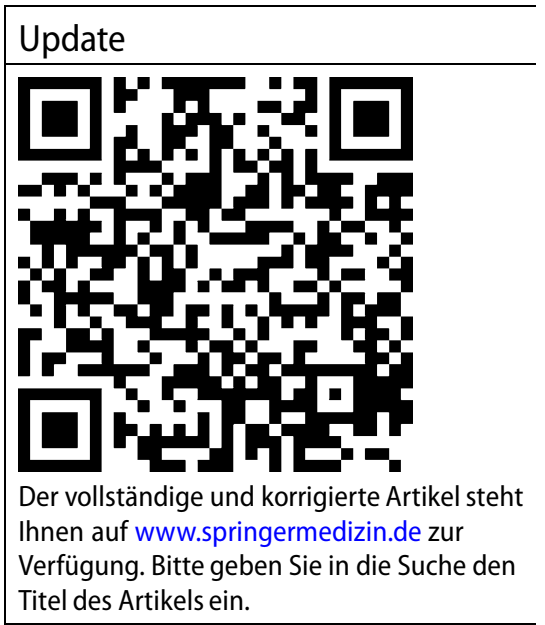

Erratum zu:

Anaesthesist 2021

https://doi.org/10.1007/s00101-021-

00940-9

In dem ursprünglichen Artikel wurden die Kollaboratoren der Studie, die als institutioneller Autor unter „HandiCAPInvestigators" zusammengefasst worden sind, nicht korrekt wiedergegeben. Dies wurde nun korrigiert. Wir bitten, den Fehler zu entschuldigen.

\section{Korrespondenzadresse}

\section{PD Dr. Melanie Meersch}

Klinik für Anästhesiologie, operative Intensivmedizin und Schmerztherapie, Universitätsklinikum Münster Albert-Schweitzer-Campus 1, Geb. A1, 48149 Münster, Deutschland meersch@uni-muenster.de
Die Online-Version des Originalartikels ist unter https://doi.org/10.1007/s00101-021-00940-9 zu finden. 